\begin{abstract}
Apologies can have desirable effects on the reduction of anger and may foster forgiveness. Yet, we know little about the effectiveness of apologies across different cultures. In this research, we distinguished two important components of apologies: admission of blame by the self and the expression of remorse for the plight of the other. We investigated how these two components resonate with cultural values associated with dignity and honor. Results revealed that although an apology increased forgiveness in both cultures, honor-culture members tended to forgive less and retaliate more than dignity-culture members, after an apology. This cultural difference was mediated by the extent to which honor-culture (vs. dignity-culture) members perceived the apology to express (less) remorse and thus be (less) sincere.
\end{abstract}

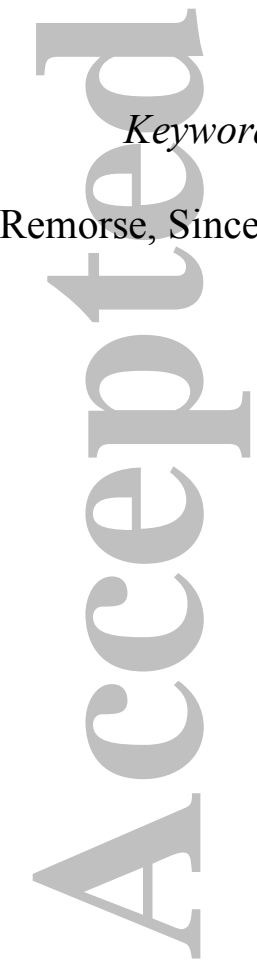

This is the author manuscript accepted for publication and has undergone full peer review but has not been through the copyediting, typesetting, pagination and proofreading process, which may lead to differences between this version and the Version record. Please cite this article as doi:10.1111/jasp.12460. 


\section{Sorry seems to be the hardest word: cultural differences in apologizing effectively}

The goal of the current research is to contribute to knowledge on how to manage workplace conflict in intercultural work teams. We investigate apologies as a tool to deescalate conflicts and to explore the role of cultural ideals of honor and dignity in this process (see also, Leung \& Cohen, 2013). Given that organizations are becoming increasingly diverse, it is essential to gain a better understanding of how cultural differences may influence the development, escalation and resolution of work-place conflict. Unfortunately, the framework of cultural ideals has rarely been applied to the domain of organizational psychology or team performance (Aslani et al., 2016; Beersma, Harinck, \& Gerts, 2003; Gelfand et al., 2015). Moreover, most studies have examined conflict escalation whereas conflict resolution has received hardly any attention (Cohen \& Nisbett, 1994; Cross, Uskul, Gerçek-Swing, Alözkan, \& Ataca, 2013; IJzerman, Van Dijk, \& Galluci, 2007; Shafa, Harinck, Ellemers, \& Beersma, 2015). Yet, we increasingly interact with people from different cultures, for instance in culturally diverse teams at work.

Apologies have been shown to have desirable effects on the reduction of anger and aggression of victims (Ohbuchi, Kameda, \& Agarie, 1989; Zechmeister, Garcia, Romero, \& Vas, 2004), and may also foster forgiveness towards the transgressor after perceived violations (Merolla, Zhang, \& Sun, 2013; Tomlinson, Dineen, \& Lewicki, 2004). Although the use of apologies is a universal component of human interactions, we argue that its effectiveness in reducing interpersonal animosity may differ across cultures. That is, different cultural value systems entail diverging norms and expectations for interpersonal conduct, which may advance the development, escalation, and resolution of conflicts in different ways (Aslani, Ramirez- 
Marin, Semnani-Azad, Brett, \& Catherine, 2013; Brett, 2000; Holt \& DeVore, 2005; Oetzel \& Ting-Toomey, 2003; Shafa et al., 2015; Triandis, 2000).

\section{Framework of cultural ideals}

What seems reasonable or appropriate in terms of forgiveness and retaliation may differ between individuals, but is also likely to depend on people's cultural background. However, previous research has rarely considered the effectiveness of apologies in the context of cultural differences but for a few exceptions (e.g. Han \& Cai, 2010; Maddux, Kim, Okumura, \& Brett, 2011). Moreover, current insights on cultural differences (Aslani et al., 2013; Leung \& Cohen, 2011) go beyond the traditional distinction between individualistic and collectivistic cultures. The framework guiding this more fine-grained analysis explicitly considers cultural logics, that weave together shared values, norms and practices around a central cultural ideal (Leung \& Cohen, 2011). These ideals in turn prescribe culturally appropriate behaviors and aspirations. Besides dignity (present in highly individualistic cultures) and face (present in highly collectivistic cultures), this framework identifies a third cultural ideal, that is honor. For the purpose of the current research, we focus on two cultures, which represent the honor and dignity ideal. Our current interest is to examine cultural differences in the effectiveness of an apology, as a way to mitigate hostile responses following an offensive encounter. In this context, it is most relevant to examine a culture endorsing the honor ideal, as prior research suggests that the honor logic prescribes an antagonistic emotional response to an offensive encounter (Aslani et al., 2016; Leung \& Cohen, 2011). We contrast the honor culture with a culture based on dignity. This cultural contrast is the most meaningful in view of our research question, because of essential differences in the way people are perceived and valued, namely in terms of personally conferred worth (dignity) vs. socially conferred worth (honor). We 
anticipate this difference in emphasis affects the effectiveness of apologies, and guides the ingredients that are necessary for apologizing effectively. We are aware that both honor and face cultures, share an emphasis on socially conferred worth. However, in view of our aim to examine conflict resolution and retaliation, face cultures may be less informative as they prescribe a more avoidant and suppressed conflict management style and condemn interpersonal retaliation (Aslani et al., 2013; Boiger, Güngör, Karasawa, \& Mesquita, 2014). Moreover, while the dignity/face comparison is relevant to the societal makeup of Northern America, the dignity/honor comparison is relevant to the European context in which this research took place.

It is also important to note that both ideals of honor and dignity play a part in defining their sense of self-worth for most people, regardless of cultural background. For example, upholding one's moral standards (personal integrity) is very important for people in both honor and dignity cultures (Rodriguez Mosquera, Manstead, \& Fischer, 2002b). Additionally, one’s self-esteem has been shown to be linked to social evaluative cues such as the sense of being included or excluded, even in dignity cultures (Leary, Tambor, Terdal, \& Downs, 1995). As such, both honor and dignity are important concepts, though there are differences in the extent to which each is considered principal in different cultures. They are also ideals (Leung \& Cohen, 2011), in the sense that they prescribe preferable behavior. People strive to adhere to these ideals, but they are not always successful or they might decide to settle for less or disregard an ideal.

Dignity is defined as the inherent value of an individual, which is at least equal to that of every other person (Ayers, 1984; Leung \& Cohen, 2011). Dignity pertains to an internalized sense of moral values and guidelines, and is characterized by loose social norms. In a dignity culture, the worth of each individual is considered intrinsic and stable. People are born with dignity and others cannot take it away. Dignity thus entails not having to rely on others' approval 
in order to be valued. Correspondingly, individuals in a dignity culture are unworried about others' disapproval, as this is unlikely to jeopardize their worthiness. As such, it has been shown that people in a dignity culture operate autonomously and are unlikely to be influenced by opinions of others than people in an honor culture are (Kim, Cohen, \& Au, 2010; Leung \& Cohen, 2011).

Honor is an archaic concept in some societies, but in many other societies, it still plays an important role in how people define themselves, the extent to which they are valued by the group they belong to and the way they interact with other members of their society (Gilmore, 1987; Guerra, Giner-Sorolla, \& Vasiljevic, 2013; Miller, 1993; Peristiany, 1965; Schneider, 1969). Honor is typically defined as the value of an individual in his own eyes, as well as in the eyes of others (Pitt-Rivers, 1965). As such, honor — besides representing an internal quality — is something social. Honor not only communicates the esteem of individuals, bestowed upon them by others, it also indicates the sensitivity of the individual for that same public opinion (Gilmore, 1987). Maintaining a positive social image and protecting one's reputation to ensure favorable evaluations is key among those adhering to honor (Rodriguez Mosquera, Manstead, \& Fischer, 2000,2002a).

Much of prior research involving the cultural values of honor and dignity has focused on insults or provocations, and their role as catalysts in conflict escalation and retaliation (Beersma et al., 2003; Cohen, Vandello, Puente, \& Rantilla, 1999; IJzerman et al., 2007; May, Monga, \& Kalaignanam, 2015; Rodriguez Mosquera, Fischer, Manstead, \& Zaalberg, 2008). Hardly any work has considered how such consequences can be prevented or mitigated, especially not within an organizational domain. The present research aims to gain a better understanding of how 
effective apologies are in de-escalating conflicts among people from different cultures. This is essential for organizations, which are becoming increasingly culturally diverse.

\section{Culture and work-place conflict}

The experience of offenses and how to overcome them is particularly relevant when honor is at stake, as one's personal sense or worthiness depends on positive evaluations by others (Rodriguez Mosquera et al., 2008; Shafa, Harinck, Ellemers, \& Beersma, 2014). In this logic, confrontations need to be answered vigorously in order to protect or maintain an honorable image. Accordingly, studies in organizational behavior have reported that honor-culture members are competitive negotiators (Aslani et al., 2016). Compared to individuals from a dignity culture, honor-culture members display higher levels of anger, and more forceful conflict management strategies after offensive interactions (Aslani et al., 2013; Beersma et al., 2003). Because dignity is independent on one's social standing, treatment by others does not directly impact one's sense of worth (Kim et al., 2010). As a result, a person of dignity should not be defied by insults. Instead, in a dignity culture individuals should be reluctant to retaliate after being offended, and should stay calm and rational in the face of threats (Leung \& Cohen, 2011). Indeed, research shows that dignity culture members tend to handle conflicts more rationally and respond less vigorously to offenses compared to people from honor cultures (Aslani et al., 2016).

Based on this prior work, we expect that honor-culture members will generally report lower levels of forgiveness and higher levels of anger and retaliation than dignity-culture members following an offensive work-place encounter. In such conditions, honor norms dictate that the interpersonal ramifications of being offended -including damage to a person's social standing- need to be vindicated in order to prevent or restore loss of honor (Aslani et al., 2013; Cohen \& Nisbett, 1997; Rodriguez Mosquera et al., 2008). 
Hypothesis 1: Honor-culture members will report a lower level of willingness to forgive the offender and a stronger inclination to retaliate than dignity-culture members.

\section{The universal function of an apology}

An apology is defined as an encounter where the offender acknowledges responsibility

for an offense and expresses remorse for said offense towards the victim, sometimes also followed by the promise of atonement and compensation (Gold \& Weiner, 2000; Lazare, 2004).

Shnabel and Nadler (2008) show that in the process of reconciliation, offenders are motivated to restore their public moral image after an offense while victims are mainly concerned with restoring their sense of loss of control as a result of the transgression. Apologies function as a remedial tool by fulfilling these differential needs of both the offender and the victim. An apology presumably is effective as the offender (a) takes the blame for the offense, and (b) denounces their own prior behavior to reestablish the relationship with the offender (Goffman, 1971; Han \& Cai, 2010). In a way, admitting blame is self-focused, signaling that the offender acknowledges the inappropriateness of their prior behavior. By comparison, expression of remorse is other-focused, communicating awareness of the harm sustained by victim (Gold \& Weiner, 2000). Recent research has demonstrated that an effective apology may also consist of more components than admitting blame and expressing remorse - e.g. an explanation for the transgression or a request for forgiveness — and apologies containing multiple components may be more effective than apologies containing only a single or a few components (Kirchhoff \& Čehajić-Clancy, 2014; Lewicki, Polin, \& Lount, 2016).

Research in different domains has revealed that apologies can help to reduce hostility, restore trust and evoke cooperation after offenses. For example, both scenario studies and lab 
studies suggest that participants are less likely to harbor anger or aggression (e.g. Ohbuchi et al., 1989), and more likely to forgive an offender (e.g. Gold \& Weiner, 2000; Tomlinson et al., 2004) after receiving an apology than when no apology is offered. In economic bargaining games people are more willing to accept an unfair offer, when it is accompanied by a social account such as an apology than when it is not (e.g. Dijke \& Cremer, 2011). Likewise, an apology can effectively restore violated trust after initial non-cooperative responses in a trust game (e.g. Bottom, Gibson, Daniels, \& Murnighan, 2002; Schweitzer, Hershey, \& Bradlow, 2006). More generally, a recent meta-analysis on different antecedents of forgiveness indicates that an apology is among the most reliable precursors of forgiveness (Fehr, Gelfand, \& Nag, 2010). Work on team performance and leadership indicates that leaders who apologize sincerely after a wrongdoing are more likely to promote forgiveness, trustworthiness and organizational commitment among followers than leaders who don't apologize (Basford, Offermann, \& Behrend, 2014). Relevant to this research, apologies are also effective in reducing work-place conflict (Ayoko, 2016; Hui, Lau, Tsang, \& Pak, 2011; Struthers, Eaton, Mendoza, Santelli, \& Shirvani, 2010; Walfisch, Van Dijk, \& Kark, 2013).

Researchers have rarely considered cultural differences when studying the effectiveness of apologies as a way to prevent (workplace) conflict escalation. When cultural differences were considered, results were in line with the general expectation that -across different culturesapologizing is more effective than not apologizing (Han \& Cai, 2010; Maddux et al., 2011; Merolla et al., 2013). Apologies work, because they convey that an offender is aware of having harmed the victim, that the offender regrets the violation and sympathizes with the victim, and implicitly assures that the behavior is not likely to happen again. Our second hypothesis builds on these previous findings. 
Hypothesis 2: In both honor and dignity cultures, an apology (vs. no apology) will increase the willingness to forgive the offender and reduce the inclination to retaliate.

\section{Culture and apologies}

Notwithstanding these beneficial effects that have been documented, apologies can also function as a double-edged sword: Instead of fostering forgiveness, an apology may increase the attribution of blame. For example, apologizing for a prior transgression is less likely to foster forgiveness when the transgression was made intentionally vs. unintentionally (Struthers, Eaton, Santelli, Uchiyama, \& Shirvani, 2008). As a result, apologizing may sometimes backfire, resulting in stronger retaliation by the victim. This is especially likely to happen when the apology is perceived as insincere (e.g. Zechmeister et al., 2004). Indeed, a number of studies report that in order to be truly effective an apology needs to be sincere (Ayoko, 2016; Basford et al., 2014; Tomlinson et al., 2004; Zechmeister et al., 2004). Thus, while apologies may be effective, apologizing effectively is a complex undertaking in which perceived responsibility, remorse and sincerity all play a role.

We posit that cultures are likely to differ in which type of apology is most effective. An apology is particularly effective when the components it contains are consistent with the way a person's self-worth is defined (Fehr \& Gelfand, 2010), in congruence with culture-specific norms. For the purpose of this study, we focus on the two components of admitting blame and expressing remorse. We choose this focus for two reasons. First, even in studies examining multiple components of apologies, these two components are structurally rated among the most important (Kirchhoff \& Čehajić-Clancy, 2014; Lewicki et al., 2016). Second, these two 
components have important bearing on cultural differences in the representations people construe and how they evaluate themselves and others in a social setting. Given that these two components of an apology clearly have different functions and foci, the effectiveness of admitting blame and expressing remorse are likely to differ, depending on cultural background of the victim. This is predicted to have important implications for which type of an apology is likely to be most effective in each cultural context.

As argued above, dignity is characterized by an independent self-construal, emphasizing autonomy and responsibility, positive self-evaluations and the prevention of guilt (Leung \& Cohen, 2011). Admission of blame is self-oriented and indicates an offender's acceptance of guilt and responsibility for perpetrating a transgression. This should specifically resonate with victims hailing from a dignity-culture. When the perpetrator does not recognize being the one at fault, the victim might be inclined to assert himself in order to indicate that. An apology in which the perpetrator takes the blame however, releases the victim from the responsibility for a contentious situation, reducing his/her need for retribution and promoting forgiveness. Indeed, research shows that in the course of reconciliation, perpetrators from a dignity culture (i.e., Americans) tend to rely on providing an account for their transgression (Sugimoto, 1997) and they equate apologizing with admitting personal blame (Maddux et al., 2011).We expect targets of transgressions to mirror this preference in that in a dignity culture victims will be more inclined than in an honor culture to forgive an offender who takes blame for the offense.

In an honor-culture, priorities are likely to be different. Honor is characterized by a relational self-construal, emphasizing the importance of respect and positive social evaluations, and focusing on the prevention of shame as a primary concern (Rodriguez Mosquera, et al., 2008). Expression of remorse is other-oriented and signals the offender's shame for the 
transgression, forbearance and self-deprecation in order to restore the relationship. This should particularly resonate with members of an honor culture. For them, an apology is satisfactory to the extent that it reinstates the victims' social worth and signals that the perpetrator regrets having offended them. Therefore, we expect that in an honor culture, providing an apology, which expresses true remorse, might be essential to forgive and forego revenge.

Hypothesis 3: An apology in which the offender takes blame for a violation will mainly increase willingness to forgive and reduce inclination to retaliate among dignity-culture (vs. honorculture) members.

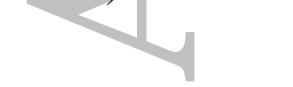

Hypothesis 4: An apology in which the offender expresses remorse after a violation will mainly increase willingness to forgive and reduce inclination to retaliate among honor-culture (vs. dignity-culture) members.

Finally, based on prior research, which indicates that apologies are effective to the extent that they are perceived as sincere (Basford et al., 2014; Tomlinson et al., 2004; Zechmeister et al., 2004), we anticipate that the effect of type of apology on participants' willingness to forgive and need for retaliation relates to the level of perceived sincerity of the apology. However, the sincerity of the apology may be rated differently, depending on the cultural ideals of the victim and how characteristics of the apology (acknowledging blame vs. expressing remorse) relate to culture-specific concerns (see Figure 1 for entire model). 
Hypothesis 5: The effect of an apology on forgiveness/retaliation is mediated by the perceived sincerity of the apology.

$<$ Figure 1 about here $>$

\section{Current research}

In the current research, we separate the two components of an apology (admitting blame and showing remorse) and compare responses of members of an honor culture and a dignity culture. We investigate how each component influences the willingness to forgive an offender and the desire to retaliate an offense the among research participants from the Netherlands and Turkey. According to previous research (Shafa, et al., 2015; Uskul, et al., 2012; Van Osch, Breugelmans, Zeelenberg, \& Bölük, 2013) participants from these two countries may be considered prototypical representations of a culture endorsing the dignity ideal — in case of the Netherlands - and honor ideal — in case of Turkey. As such, the comparison between individuals living in these countries offer a valid and relevant research context for the current study. We expect cultural differences in the extent to which an offense provokes a hostile response (H1). Moreover, we suspect that for both cultural groups, an apology will result in higher levels of forgiveness and lower levels of retaliation than when no apology is offered (H2). However, we also argue that because the two components have different functions and foci, they will be more or less relevant for an effective apology depending on cultural background (H3, H4). Finally, we expect that the effect of an apology on forgiveness and retaliation is mediated 
by the perceived sincerity of the apology (H5). We test our predictions regarding the differential impact of admittance of blame vs. expression of remorse for apologizing effectively in different cultures, in an experimental study. Participants respond to different work-place conflict scenarios, which describe a range of norm violations (e.g. insult, violation of autonomy and a combination of both). We investigate how different apologies affect participants' inclination to retaliate, and willingness to forgive an offender.

We used three different scenarios to increase the generalizability of our findings across different types of conflicts and apologies. This also allowed us to examine violations of different norms. For example, the one scenario represented an offense, which violates a person's integrity by falsely accusing them of a moral transgression. This type of offense has been shown to trigger stronger antagonism in an honor culture (Cross et al., 2013). The another scenario described a situation which violated a person's autonomy, which is more central to people in a dignity culture than in an honor culture (Rodriguez Mosquera et al., 2002b). The third scenario described a situation in which both integrity and autonomy norms were violated at the same time. By considering different violations, we were able to control for the notion that different values may be more central in different cultures.

\section{Method}

\section{Participants}

Subjects were undergraduate students, recruited at the social sciences faculties of a University in the center of the Netherlands (dignity), and a university in Istanbul, Turkey (honor). 159 Dutch subjects and 178 Turkish subjects participated in this study, accumulating to a total of 337 subjects. The Dutch sample consisted of native Dutch participants (born in the Netherlands and having a Dutch nationality), with an average age of $20.04(\mathrm{SD}=2.25)$. The 
Turkish sample consisted of native Turkish participants (born in Turkey and having a Turkish nationality), with an average age of $21.54(\mathrm{SD}=2.96)$. The Dutch sample consisted of 117 (74\%) female participants and the Turkish sample consisted of 128 (72\%) female participants. Age nor gender significantly affected outcomes reported in this study. Since both samples were quite similar in terms of education, age, gender, and both samples were attending a university in an urban environment, we considered them to be highly comparable.

All participants consented to voluntary participation in an online survey, investigating cultural differences in the way people manage work-place conflicts. To encourage participation, two tablet computers were raffled among all participants who completed the survey, one at each university. Subjects who wanted to participate in the raffle left behind their email address after completing the survey and were contacted via email, to inform them of the outcome of the raffle.

\section{Design}

The study had a 2 (culture: honor vs. dignity) by 2 (blame factor: yes vs. no) by 2 (remorse factor: yes vs. no) between-subject design. This resulted in four conditions in each cultural group, in which the offender either apologized by only accepting blame, or by only showing remorse, or both, or did not apologize at all. Participants were randomly assigned to one of the four apology conditions. Each participant was presented with three different scenarios in random order; the nature of the scenario was treated as a within-subject factor. Participants' willingness to forgive and retaliate the transgression were the main dependent variables.

\section{Instrument and Procedure}

The survey was first developed in English, and then translated by sworn translators into Dutch and Turkish. Participants received a link to the online survey in their native tongue. After 
reading the informed consent, the survey started, consisting of three sections. In the first section, we measured cultural values associated with honor and dignity.

In the second section, three scenarios were presented in random order, each describing a work-place conflict. In the Liar scenario, participants read about being falsely accused by a fellow colleague of misplacing important documents and being called a dirty liar in the presence of other team members. In the $C V$ scenario, participants read about their $C V$ being held back from an application procedure by their HR officer, without their consent, causing them to miss out on the opportunity to be assessed for a potential promotion. In the Freeloader scenario, participants read about a fellow colleague spreading rumors that they were a freeloader by taking undue credit for closing an important contract (see Appendix A for a full description of the scenarios).

Each scenario was followed by the same series of questions. First, participants indicated how angry they would be in said scenario as a way to check for the gravity of each offense. Then participants read a follow-up description of the situation, in which the offender apologized in different ways, depending on the condition each participant was in. The offender either took blame for the offense, or showed remorse for the offense, did both, or did not apologize at all. When the offender did apologize, participants were presented with an expression of apology ("I am sorry"), followed by different types of elaborations, depending on experimental conditions. The exact description of the different apologies is included in the appendix. In the no-apology condition, no apology or elaboration was offered. Next, participants indicated their willingness to forgive the offender and retaliate. In addition, we checked to what extent participants felt that the offender took responsibility for the offense, expressed remorse for the offense and whether the apology was perceived as sincere (this final measure was excluded in the no-apology condition). 
In the final section of the questionnaire, we collected demographic information of the participants, including age, gender and country of birth. Participants were debriefed, thanked for their cooperation and given the opportunity to take part in the raffle using their email address.

\section{Measuring cultural values}

Honor. To indicate honor, we used the five-item honor scale assessing concerns for maintaining and protection of one's personal and family reputation, which is considered the key aspect in which honor culture members differ from dignity culture members (Rodriguez Mosquera et al., 2008). For example, participants were asked to what extent people in their culture were concerned with "others seeing them as someone who deserves respect" $(1=$ not at all, $7=$ very $m u c h)$. The internal consistency was $(\alpha=.70)$ for the Dutch sample and $(\alpha=.82)$ for the Turkish sample.

Dignity. Dignity was measured using a four-item scale assessing people's beliefs about the importance of staying true to their personal convictions and not being influenced by other people's opinion (Leung \& Cohen, 2011). For example, participants were asked to indicate to what extent people in their culture believed that "how others treat them is irrelevant to their worth as a person" ( $1=$ not at all, $7=$ very much $), \alpha=.70$ for the Dutch sample and $\alpha=.88$ for the Turkish sample.

\section{Scenario and manipulation checks}

Anger. Three questions were included to assess participants' anger in the situation described. We included this measure before participants read about the apology, in order to have an indication of the severity of the offense, irrespective of whether or not the offender apologized. Participants indicated to what extent they "would feel angry right now", "would feel mad right now", and "would feel irritated right now" ( $1=$ not at all, $7=$ very much $)$. Initial 
analyses revealed that including the third item resulted in unsatisfactorily low internal consistency levels $(\alpha$ 's $<.60)$. Therefore, we only included the first two items in the final analyses. Correlations between the two items were $(r=.83)$ for the Liar scenario, $(r=.92)$ for the CV scenario, and $(r=.83)$ for the Freeloader scenario.

Taking responsibility and expressing remorse. To see whether participants actually felt that the offender took responsibility or expressed remorse by apologizing, two four-item scales were used. Taking responsibility was measured by transforming items from the Blame Attribution Scale (Bradfield \& Aquino, 1999) to fit the current context. For example, one item of the original scale is "They are guilty". In this study, the item was rephrased to specify, "Ifeel that this person admits to being guilty of the offense" (1 = totally disagree, $7=$ totally agree $)$. Internal consistency levels were $\alpha=.93$ for the Liar scenario, $\alpha=.89$ for the CV scenario, and $\alpha$ $=.91$ for the Freeloader scenario.

Expressing remorse was measured by transforming four items of the Remorse Construct Rating Form (Brooks \& Reddon, 2003) to reflect that the offender in the given scenario experienced negative feelings and acknowledged the victim's pain, e.g. "I get the feeling that the colleague thought he/she was not a good co-worker" ( $1=$ totally disagree, $7=$ totally agree $), \alpha=$ .84 for the Liar scenario and the CV scenario, and $\alpha=.80$ for the Freeloader scenario.

\section{Main dependent measures}

Forgiveness and retaliation. Inclinations to forgive the transgressor and to retaliate after the apology,were assessed using two four-item scales, based on the Revenge and Forgiveness Behavior scales by Bradfield and Aquino (1999). For example, participants indicated to what extent they "would be willing to forgive this person" and to what extent they "would want to get even" respectively $(1=$ not at all, $7=$ very much $)$. For forgiveness, internal consistency was $\alpha=$ 
.92 for the Liar scenario, $\alpha=.90$ for the CV scenario, and $\alpha=.87$ for the Freeloader scenario.

Internal consistency levels for retaliation were $\alpha=.90$ for all three scenarios. Though forgiveness and retaliation do not necessarily have to be inverse related, they may be considered representing two extremes on a single continuum. Displays of retaliation surely exclude forgiveness, and vice versa. The response of someone who decides not to retaliate and not to forgive could represent the neutral point between these two. Importantly, forgiveness and retaliation showed a statistically significant and substantial negative correlation in our study, this was $r=-.49$ in the Liar scenario, $r=-.47$ in the CV scenario, and $r=-.51$ in the Freeloader scenario, all $p \mathrm{~s}<.001$. Admittedly, these correlations are not so strong that they indicate retaliation and forgiveness measures are redundant with each other. However, they do suggest that these can be considered as different and opposing facets of the response provided.

Exploratory Principal Component Analyses with Varimax rotation on forgiveness and retaliation items revealed just one factor with Eigenvalue above 1 (3.0, 50\% variance explained) with high positive loadings for retaliation and high negative loadings for forgiveness. The combined scale consisting of all forgiveness items and reversed retaliation items was also internally consistent $(\alpha=.80)$ and deleting one or more items did not improve the reliability. Furthermore, analyses did not reveal any systematic differences between analyzing the combined forgiveness/retaliation scale and analyzing the two scales separately. Therefore, we reverse coded the retaliation scale and averaged both measures to create a single scale representing participants' behavioral inclinations with high scores indicating a strong willingness to forgive and low scores representing strong retaliatory intentions.

Sincerity. The four-item Apology Sincerity scale (Basford et al., 2014) was adapted to the current context and included to assess the perceived sincerity of the apology (e.g. "My 
colleague's apology was sincere”, $1=$ totally disagree, $7=$ totally agree), $\alpha=.95$ for the Liar scenario and $\alpha=.97$ for the CV scenario and the Freeloader scenario. Please note that sincerity was not measured in the no-apology conditions. Therefore, all main and interaction effect on sincerity only pertain to the three conditions were some form of apology was offered.

\section{Results}

\section{Cultural values}

We analyzed cultural differences in endorsement of cultural values associated with honor and dignity, using ANOVAs to compare responses provided by participants from Turkey with responses observed among participants from The Netherlands. These analyses revealed a significant main effect of culture on both dimensions with mean differences in the expected direction. Turkish participants were more inclined to endorse honor-related values $(M=5.82, S D$ $=.97)$, compared to Dutch participants $\left(M=4.73, S D=1.01 ; F(1,335)=102.29, p<.001, \eta_{\mathrm{p}}{ }^{2}=\right.$ .23). Dutch participants more strongly endorsed dignity-related values $(M=5.54, S D=.90)$, than did Turkish participants $\left(M=3.89, S D=1.39 ; F(1,335)=162.77, p<.001, \eta_{\mathrm{p}}{ }^{2}=.33\right)$. These findings corroborate that the Turkish sample in this study can be perceived as representing an honor-culture and the Dutch sample as a dignity-culture.

\section{Scenario check}

Anger. Next, we analyzed the level of anger participants reported after each scenario, but before the apology was offered, using a mixed design ANOVA with culture as between-subject variable and type of scenario as within-subject factor. The within-subject effect was significant $\left(F(2,670)=21.85, p<.001, \eta_{\mathrm{p}}{ }^{2}=.06\right)$, indicating that the Freeloader scenario $(M=6.23, S D=$ 1.09), which contained the most severe transgression, was considered more upsetting than the 
Liar scenario $\left(M=5.80, S D=1.38 ; F(1,335)=59.04, p<.001, \eta_{\mathrm{p}}{ }^{2}=.15\right)$ and the CV scenario $\left(M=5.90, S D=1.39 ; F(1,335)=21.36, p<.001, \eta_{\mathrm{p}}{ }^{2}=.06\right)$.

The culture by scenario type interaction was significant $\left(F(2,670)=21.85, p<.001, \eta_{\mathrm{p}}{ }^{2}\right.$ $=.06$ ). Pairwise comparisons (see Figure 2) revealed that honor-culture participants were marginally more upset than dignity-culture participants in response to the Liar scenario $(F(1,335)$ $\left.=3.074, p=.08, \eta_{\mathrm{p}}{ }^{2}=.01\right)$, that is, when their integrity was at stake. By contrast, dignity-culture participants were more upset than honor-culture participants in response to the CV scenario $\left(F(1,335)=15.34, p<.001, \eta_{\mathrm{p}}{ }^{2}=.04\right)$ which violated their autonomy. No differences between the two samples of participants were found in the Freeloader scenario, where both integrity and autonomy values were at stake.

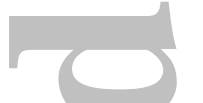

$<$ Figure 2 about here $>$

These findings indicate that generally speaking, participants considered the Freeloader scenario most serious, followed by the CV scenario and the Liar scenario. They are also in line with our assumption that the Liar scenario would strongly antagonize honor concerns (integrity), while the CV scenario would strongly antagonize dignity concerns (autonomy) and that the freeloader scenario would constitute a combination of both elements. Nevertheless, the main effect of culture was not significant, demonstrating that overall anger levels were equal between cultures when considering all scenarios. Moreover, analyzing the three scenarios separately did not yield any further systematic differences related to the interaction of culture by type of scenario on the forgiveness, retaliation, and sincerity measures. In conclusion, culture did not interact with type of scenario in predicting outcomes on the main dependent variables. Therefore, 
we report the results of analyses conducted after collapsing the data over the three different violation scenarios.

\section{Manipulation checks}

Perceived responsibility and remorse. We assessed the effectiveness of the apologies in conveying blame and remorse by submitting perceived responsibility and perceived remorse to ANOVAs with culture, blame factor and remorse factor as independent variables. Statistics are presented in Table 1, means are depicted in Figure 3 (responsibility taken) and Figure 4 (expressed remorse). As can be seen from these results, almost all main effects and interactions effects (except for the main effect of culture on perceived responsibility taken) were significant. With regard to our hypotheses, we will focus on the main effects of culture, the main effects of blame and remorse, and the three-way interaction of culture by blame factor by remorse factor.

$<$ Table 1 about here $>$

Main effect of culture. Only the remorse measure showed a main effect of culture $\left.F(1,335)=12.41, p<.001, \eta_{\mathrm{p}}{ }^{2}=.04\right)$, indicating that overall, honor-culture participants $(M=$ $3.42, S D=1.17$ ) perceived that the offender expressed less remorse than dignity culture participants $(M=3.82, S D=1.26)$, even though the actual apology was identical. This may be the result of cultural differences causing members of an honor culture having firmer expectations of what an apology should entail. In the case of perceived responsibility, we did not find a significant main effect of culture $(F>1)$, indicating that participants from both cultural groups perceived that the offender took responsibility to an equal extent. 
$<$ Figure 3 about here $>$

$<$ Figure 4 about here $>$

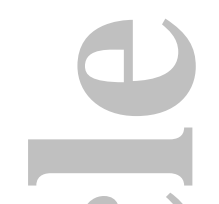

Main effect of blame factor and remorse factor. In case of perceived responsibility taken, we found similar significant main effects for both experimental factors (see Table 1). This means that the impact of the apology was comparable, regardless of whether the apology conveyed blame (vs. not) or whether the apology conveyed remorse (vs. not). In both cases, participants felt that the transgressor took more responsibility for the wrongdoing when communicating vs. not communicating an apology (see Figure 3).

The same was true for the expressed remorse measure, given that the effects of both experimental factors were significant (see Table 1). Here too, we found that both an apology with admission of blame (vs. not) and an apology with remorse (vs. not), resulted in participants' perception that the transgressor expressed more remorse for the wrongdoing. In other words, all apology conditions conveyed blame taking and remorse showing to the same extent and significantly more so than the control condition in which there was no apology (see Figure 4).

Three-way interactions. These main effects were qualified by significant three-way interactions. The three-way interaction effect for perceived responsibility (see Table 1) was marginally significant. Further inspection revealed that, although participants in all three apology conditions felt that the transgressor took more responsibility for the wrongdoing than in the noapology condition, this effect was much stronger in the dignity group than in the honor group. Thus, any type of apology — either, admitting blame, expressing remorse, or both — resulted in 
more perceived responsibility taking in both cultures, but particularly in the dignity group (see Figure 3).

The three-way interaction effect on perceived remorse was also significant (see Table 1). The relevant means signal that only dignity-culture participants perceived any expression of remorse in each of the three apology conditions compared to the no-apology condition. Honorculture participants on the other hand did not perceive more expression of remorse in the three apology conditions compared to the no-apology condition (see Figure 4).

Overall, these results suggest that the apologies were effective in signaling admittance of blame, but this was independent of type of apology condition. In other words, regardless of the type of apology, participants from both cultures felt that offenders took blame when they apologized (relative to the no-apology condition). In the case of perceived remorse, only dignityculture participants experienced that the offender showed increased remorse by apologizing. This was also independent of type of apology condition. Honor-culture participants did not feel that the offender expressed remorse by apologizing in any of the apology conditions. These findings are in line with the general notion that people have implicit cultural expectations about what constitutes an effective apology, and respond differently to them.

\section{Test of hypotheses}

To test Hypotheses 1 through 4, we assessed the main and interaction effects of an ANOVA with culture, blame factor and remorse factor as independent variables and forgiveness/retaliation inclinations as dependent variable

Hypothesis 1. To assess Hypothesis 1, that an offense generally triggers more antagonistic responses among honor culture members compared to dignity culture-members, we looked at the main effect of culture on behavioral inclinations. This effect was significant 
$\left(F(1,335)=13.04, p<.001, \eta_{\mathrm{p}}{ }^{2}=.04\right)$. Inspection of the means revealed that across the board dignity participants $(M=4.47, S D=1.05)$ were more likely to forgive- - and less likely to retaliate - than honor participants $(M=4.03, S D=1.19)$. Thus, honor participants were in general more inclined to show hostility towards the offender than were dignity participants.

$<$ Figure 5 about here $>$

Hypothesis 2. To test Hypothesis 2, that an apology increases the willingness to forgive and reduces the need to retaliate irrespective of culture, we examined the main effects of the two apology factors. Both main effects were significant, $F(1,335)=6.10, p=.014, \eta_{\mathrm{p}}{ }^{2}=.02$ for blame factor and $F(1,335)=4.38, p=.037, \eta_{\mathrm{p}}{ }^{2}=.01$ for remorse factor. Both effects indicated that offering some form of apology was more effective in increasing forgiveness — and reducing retaliation - than offering none (see Figure 5).

Hypothesis 3 and 4. Hypotheses 3 and 4 predicted that the effect of apologizing would depend on whether the perpetrator of the offense took the blame or expressed remorse, in an honor or dignity culture context. To assess these two hypotheses, we examined the second and third order interactions of culture, blame factor and remorse factor on willingness to forgive and retaliate. None of these effects were significant (Fs $<1.6, \mathrm{~ns})$, meaning that culture did not interact with the apology factors in any way to influence forgiveness and retaliation. We suspect this is the case because participants did not perceive the different type of apologies as distinct, i.e. one conveying an admission of blame and the other conveying an expression of remorse (see manipulation checks).

Hypothesis 5. To assess the mediating role of sincerity in the effectiveness of an apology, we first analyzed perceived sincerity of the apology using ANOVA. Please note that 
sincerity of the apology was not measured in the no-apology condition. Therefore, we analyzed this measure with culture and condition (blame vs. remorse vs. both) as independent variables (see Figure 6). Results only revealed a main effect of culture $\left(F(1,335)=26.13, p<.001, \eta_{\mathrm{p}}{ }^{2}=\right.$ .10). Honor-culture participants perceived the apologies to be less sincere $(M=3.43, S D=1.22)$ than dignity-culture participants $(M=4.14, S D=.96)$. The main effect of apology condition and the culture by apology condition interaction effect were not significant $(F \mathrm{~s}<1.2$, ns $)$. These findings do not support Hypothesis 5 regarding the mediating effect of apology sincerity.

$<$ Figure 6 about here $>$

\section{Additional analyses}

Thus far, we found that the manipulation of the content of the apology was not effective, resulting in similar levels of forgiveness and retaliation in the different apology conditions.

Consequently, our hypotheses regarding the differential impact of these components on forgiveness and retaliation after an apology in different cultures (H3 and H4) and the mediating effect of sincerity (H5) were not supported. However, there was indirect evidence for the primacy of expressing remorse in order to apologize sincerely to someone from an honor culture (H4 and H5). Contrary to dignity-culture participants, honor-culture participants reported that the offender did not express remorse or apologized sincerely beyond the baseline in any one of the apology conditions. It seems that to them, the offender did admit blame, but was not remorseful enough. This pattern is at least partially in line with our reasoning that those in an honor culture have higher standards for expressed remorse in an apology, and may be revealing for why honorculture members did not forgive to the same extent as dignity-culture participants. 
Based on this pattern, we revisited Hypothesis 4 and 5, to examine what constitutes an effective and sincere apology in different cultures, by performing additional regression analyses with bootstrapping (5000) as recommended by Hayes (2013). Given the lack of cultural moderation by different apology conditions and equal levels of perceived blame taking, we focused on cultural differences in expressed remorse. In our analysis, we included culture as independent variable, remorse and sincerity as sequential mediators and the forgiveness/retaliation measure as outcome variable. The results of this analysis are presented in Figure 7 - and were similar to those when analyzing the forgiveness/retaliation measure as two separate measures.

$<$ Figure 7 about here $>$

The results of this analysis show that the inclination to forgive less and retaliate more among Turkish participants, in comparison to Dutch participants, is mediated by their lower perception of perceived remorse, expressed through the apology, and consequent lower sincerity of the apology. This relationship fully mediated the effect of culture on forgiveness/retaliation, as the relationship between culture and behavioral inclinations was no longer significant after inclusion of the mediators. The only pathway which did remain significant was the mediation pathway through remorse and sincerity $(B=.71, S E=.20 ; C I 95 \%=.37-1.17)$. These outcomes (indirectly) confirm Hypotheses 4 and 5, demonstrating that indeed, the (lack of) expression of remorse is a vital part of apologizing sincerely and effectively for those in a highhonor context. Notably, perceived blame was not a reliable mediator for the effect of culture on 
sincerity or forgiveness/retaliation. Including this measure in the model rendered all mediation paths insignificant.

\section{Discussion}

We investigated whether and how different types of apologies affect participants' willingness to forgive an offender and inclination to retaliate, using different work-place conflict scenarios, comparing participants from two different cultures - Turkey and the Netherlands.

Our analyses of the two samples' endorsement of cultural values confirmed our assumption that honor is valued strongly in the Turkish culture while dignity is valued strongly in the Dutch culture. We also found cultural differences in the extent to which participants took offense to the transgression in each scenario, which was in line with said cultural values. However, these differences did not systematically influence further outcomes. Results further revealed that across the board honor-culture members tend to forgive less and retaliate more than dignityculture members, even after an apology. These findings were consistent with our expectations and theorizing on the relative importance of self-defense in such cultures and vigilance towards transgressions, which threaten one's honor. Nevertheless, we also found that an apology was effective in fostering forgiveness of the transgressor and reducing retaliation, irrespective of cultural background. In line with earlier research (Guan, Park, \& Lee, 2009; Han \& Cai, 2010; Merolla et al., 2013; Sugimoto, 1997), our findings corroborate that an apology is an effective tool to prevent or reduce conflict escalation in many different cultures.

However, the goal of the present research was to examine cultural differences in the way different types of apologies impact on conflict escalation and conflict resolution. To do so, we manipulated whether participants received an apology in which the offender primarily acknowledged blame for the transgression or expressed remorse for the transgression. We 
expected that acknowledgement of blame would mainly resonate with dignity-culture participants, whereas expression of remorse would mainly resonate with honor-culture participants. Nevertheless, contrary to our expectation, results indicated that participants did not perceive the apologies in the different conditions as conveying different messages of responsibility and remorse.

Although our manipulation of the content of the apology did not work as intended, we did observe some interesting culture-specific patterns. For example, while both cultural groups felt that the offender took blame by apologizing, only Dutch participants found that the offender also showed remorse. Turkish participants evaluated the apologies as not being remorseful. In line with our reasoning, Turkish (honor culture) participants had a higher standard for expressed remorse: it did not make them more responsive to remorse shown but seems to have increased the level of remorse needed to assuage their concerns - it was less easy to satisfy them in this respect. In similar vein, Turkish participants also perceived the apologies to be less sincere than Dutch participants did. This pattern suggested that same apology might have signaled insufficient remorse and therefore less sincerity for honor-culture participants compared to dignity-culture participants. Additional mediation analyses confirmed this notion by showing that the effect of culture on the (un)effectiveness of the apology was fully mediated by the extent to which Turkish participants perceived the apology to express (less) remorse and thus be (less) sincere. In order words, Turkish participants were less likely to forgive and more likely to retaliate, to the extent that they considered the apology insufficiently remorseful and hence less sincere. These findings indirectly offered evidence in support of our hypothesis regarding the primacy of remorse in apologizing effectively in honor-culture contexts. However, they do not 
reveal a similar relation between dignity culture members and the importance of perceived blame taking after an apology.

\section{Theoretical contribution}

With this research, we contribute to current insights on conflict reconciliation in different ways. Our findings show that apologizing is indeed one way to increase forgiveness and reduce the need to retaliate. This conclusion supports previous research on apologies by proving them an effective tool to reduce work-place conflict, as long as they are perceived to be sincere. Even when the conflict itself may not have been resolved entirely — as was the case in our scenariosan apology is still valuable because it can reduce hostility and normalize relations, paving the way for a more constructive interaction. Nevertheless, apologizing effectively may be easier said than done and different cultures require different methods. Our findings offer innovative insights in this area, by demonstrating in which way cultural ideals influence people's needs in conflict situations and how those needs can be remedied by offering the right type of apology. When honor is at stake, admitting blame is not enough to be forgiven. It is necessary to convey a sincere apology, particularly by expressing true remorse after a transgression.

The examination of forgiveness and conflict de-escalation among a cultural group endorsing the ideal of honor is an important contribution of our research. Much of the previous research on honor has focused on insults and their role as catalysts in conflict escalation and retaliation (Aslani et al., 2013; Beersma et al., 2003; Cohen, Nisbett, Bowdle, \& Schwarz, 1996; Cross et al., 2013; Shafa et al., 2015; Van Osch, Breugelmans, Zeelenberg, \& Bölük, 2013). Hardly any work has considered how to mitigate or prevent such consequences in order to achieve forgiveness and conflict resolution when honor is a concern. Our findings provide a first indication of how this might work, by showing that a sincere apology increases willingness to 
forgive (while reducing the need to retaliate), even among honor-culture members. Needless to say, this is a research avenue that needs to be pursued more extensively as we still know very little about ways to pursue reconciliation and forgiveness in conflicts, especially when culturally relevant concerns such as honor and social image are at stake. By considering an honor culture, we also inform the emerging cultural framework of cultural ideals (Cohen et al., 1996; Cross et al., 2014; Leung \& Cohen, 2011; Rodriguez Mosquera et al., 2008; Shafa et al., 2015; Uskul, Cross, Sunbay, Gercek-Swing, \& Ataca, 2012). Given that most studies have focused on cultural differences between dignity/individualistic cultures and face/collectivistic cultures (Brett, 2000; Holt \& DeVore, 2005; Oetzel \& Ting-Toomey, 2003; Triandis, 2000), information about responses of honor culture members is underrepresented in most of the existing knowledge of conflict reconciliation. The current research can help to fill this gap.

\section{Practical implications}

The results of this study also have important practical implications. Because of technological, economic but also recent political developments, the work force in many countries has become increasingly diverse during the past decades. This cultural diversity has the potential to enhance creativity, company performance and employee satisfaction (Joshi \& Roh, 2009;

Pitts, 2009). However, if not managed well, it can also pose a threat because it may result in jobdissatisfaction, underperformance and conflict (Barak \& Levin, 2002; Jehn, Northcraft, \& Neale, 1999; Neale, Northcraft, \& Jehn, 1999). Considering that cultural diversity may form a potential source of conflict escalation, knowing how to resolve such conflicts is very valuable. Especially because cultural differences may lie at the root of misunderstandings. Further, conflicts which remain unforgiven and unresolved may have detrimental and long-lasting effects on team performance and productivity (De Dreu \& Weingart, 2003; De Wit, Greer, \& Jehn, 2012). This 
contribution reveals how to diminish or resolve such conflicts, while taking into account differences, which ensue from cultural value endorsement. A person of dignity might forgive an offense once the offender admits blame and apologizes, as this confession releases him from guilt. However, the same apology may not be as effective when honor is at stake. In that case, the apology needs to express true remorse in order to signal that he violator respects the victim and regrets the consequences of his actions for the victim and their relationship. Only then, will the apology seem sincere enough to restore one's honor and prompt forgiveness. Team members and managers within diverse organizations could benefit from this knowledge whenever the need to reconcile a dispute may arise.

This knowledge is also beneficial to representatives who act or negotiate on behalf of international organizations located in different parts of the world, and for the purpose of international diplomacy. In in recent example, after shooting down a Russian fighter jet, which had allegedly flown over Turkish airspace, the Turkish Prime Minister Erdogan apologized to his Russian colleague Putin by stating that he "... would like to inform the family of the deceased Russian pilot that I share their pain and to offer my condolences to them. May they excuse us." (Washington Post, 2016). Cleary, the Turkish prime minster did not take blame for the incident. However, he does express remorse and compassion for the victims, which is in line with what people consider a sincere apology in his culture. The VW Diesel emission scandal is another good example of how this knowledge applies in a real world business scenario. After it became known that VW had been using software to mask true nitrogen oxide emission levels during laboratory emission tests in the USA, CEO Matthias Müller apologized to the American public (The Guardian, 2016). He stated, "We are - I am - truly sorry for that and I would like to apologize once again for what went wrong at Volkswagen", attributing the problems to technical 
errors rather than fraudulent intentions. Although he expressed true remorse, his failure to fully take account for the company's violations (which is essential in a dignity context) resulted in strong skepticism and trust in the company hardly restored after his apology.

Our findings also have broader societal implications. For example, since 2014, the world has seen a large influx of refugees from honor cultures such in the Middle-East, North-Africa and the Balkans. According to official numbers, in 2015 alone, 1,3 million registered refugees claimed asylum in a European country (Eurostat, 2016). Many of these refugees endorse different value systems than what Europe is accustomed. As a result, many people are concerned about how cultural differences may lead to misunderstanding and unrest. Particularly, given that different value systems entail different norms and expectations in interpersonal settings and may advance the development and escalation of conflicts in different ways (Shafa et al., 2015), we need to become aware of how relationships can be maintained or restored once tensions loom. The findings of research are contribute to this goal, especially because apologies are powerful tools towards forgiveness and tolerance.

\section{Limitations}

Our study is not without limitations. First, despite our effort to experimentally manipulate the content of the apology, measures indicated that this attempt was not as effective as we meant it to be. Participants perceived that the two types of apologies conveyed blame and remorse to a more or less similar extent. A particular challenge in this case was formulating an apology, which clearly expresses one component but not the other. As a result, we were only able to assess our hypothesis pertaining to the differential effects of blame and remorse through correlational analyses rather than causal inference. In order to assess the hypothesized relation 
between culture and different component of an apology, a more effective manipulation of these components is necessary.

Additionally, although we did find indirect evidence for the primacy of remorse in apologizing in an honor culture, we could not establish similar effects of the admission of blame in a dignity culture. The scenarios we used may offer an explanation for our failure to establish this. In our conflict scenarios, it was always clear who the guilty party was. As a result, even when the apology only contained an expression of remorse, it conveyed the obvious message that the perpetrator admitted culpability. Even when the perpetrator did not specifically admit guilt, it was clear from the scenario that they were to blame and admitted to it by apologizing. Therefore, for the dignity group, admission of blame was not necessarily more apologetic than expressing remorse in the current scenarios. It also might be the case that admitting blame and expressing remorse are both equally important for apologizing effectively in dignity cultures, a notion which is underlined by our data. Nevertheless, there is already some evidence suggesting that apologizing particularly serves the purpose of clarifying who is to blame in dignity cultures (Gries \& Peng, 2002; Maddux et al., 2011; Sugimoto, 1997). A possible shortcoming in this respect is that our research was focused on blame and remorse specifically. We know from recent research that apologies may entail more than these two components, and that apologies containing more components are likely to be more effective than apologies containing less components (Kirchhoff \& Čehajić-Clancy, 2014; Lewicki et al., 2016). As such, future research might also benefit from venturing beyond these two components, for instance by also looking at the use of an explanation for the transgression or by examining the impact of a specific request for forgiveness when considering cultural differences in the effectiveness of apologies. 
A third limitation pertains to the fact that current research does not necessarily inform us how to apologize effectively. Merely knowing that an unremorseful apology will be ineffective does not reveal what a truly remorseful apology should look like. Research in communication and pragmatics provides some initial clues towards this understanding. For example, studies comparing Arabic (honor) and English (dignity) apology tactics revealed that Arabs assign more gravity to their own shortcomings than the English and do not shy away from self-blame and self-deficiency in order to set things right (Al-Zumor, 2011). Similar results were found in a study comparing Jordanian (honor) and American (dignity) participants, where Jordanians used apologies that were more elaborate and were more likely to self-blame, in order to appease the victim (Bataineh \& Bataineh, 2008).

\section{Conclusion}

The goal of the present research was to identify whether apologies are an effective remedy for work-place conflicts and to find out how honor vs. dignity cultures differ in this. Based on a quasi-experimental study, comparing Turkish (honor) and Dutch (dignity) participants, we conclude that apologies indeed increase forgiveness and reduce retaliation in work-place conflicts. However, depending on the cultural context, for an apology to be effective, it needs to convey the right signal of either accepting blame or expressing remorse. Specifically, we established that when honor is a concern, an apology which is not considered truly remorseful will seem insincere and be less effective. 
[First Authors Last Name] Page 35

\section{References}

Al-Zumor, A. W. Q. G. (2011). Apologies in Arabic and English: An inter-language and crosscultural study. Journal of King Saud University - Languages and Translation, 23(1), 1928. doi:10.1016/j.jksult.2010.02.001

Aslani, S., Ramirez-Marin, J., Brett, J., Yao, J., Semnani-Azad, Z., Zhang, Z.-X., . . Adair, W. (2016). Dignity, face, and honor cultures: A study of negotiation strategy and outcomes in three cultures. Journal of Organizational Behavior, 1178-1201. doi:10.1002/job.2095

Aslani, S., Ramirez-Marin, J., Semnani-Azad, Z., Brett, J. M., \& Catherine, T. (2013). Dignity, Face, and Honor cultures: implications for negotiation and conflict management. In W. L. Adair \& M. Olekahns (Eds.), Handbook of Research on Negotiation (pp. 249-282).

Cheltenham, UK: Elgar Publishing.

Ayers, E. (1984). Vengeance and Justice. New York, NY: Oxford University Press.

Ayoko, O. B. (2016). Workplace conflict and willingness to cooperate: The importance of apology and forgiveness. International Journal of Conflict Management, 27(2), 172-198. doi:10.1108/IJCMA-12-2014-0092

Barak, M. E. M., \& Levin, A. (2002). Outside of the corporate mainstream and excluded from the work community: A study of diversity, job satisfaction and well-being. Community,

Work \& Family, 5(2), 133-157. doi:10.1080/13668800220146346

Basford, T. E., Offermann, L. R., \& Behrend, T. S. (2014). Please Accept My Sincerest Apologies: Examining Follower Reactions to Leader Apology. Journal of Business Ethics, 119(1), 99-117. doi:10.1007/s10551-012-1613-y 
[First Authors Last Name] Page 36

Bataineh, R. F., \& Bataineh, R. F. (2008). A cross-cultural comparison of apologies by native speakers of American English and Jordanian Arabic. Journal of Pragmatics, 40(4), 792821. doi:10.1016/j.pragma.2008.01.003

Beersma, B., Harinck, F., \& Gerts, M. J. J. (2003). Bound in honor: how honor values and insults affect the experience and management of conflicts. The International Journal of Conflict Management, 14(2), 75-94. doi:10.1108/eb022892

Boiger, M., Güngör, D., Karasawa, M., \& Mesquita, B. (2014). Defending honour, keeping face: Interpersonal affordances of anger and shame in Turkey and Japan. Cognition and Emotion, 28(7), 1255-1269.

Bottom, W. P., Gibson, K., Daniels, S. E., \& Murnighan, J. K. (2002). When Talk Is Not Cheap: Substantive Penance and Expressions of Intent in Rebuilding Cooperation. Organization Science, 13(5), 497-513.

Bradfield, M., \& Aquino, K. (1999). The Effects of Blame Attributions and Offender Likableness on Forgiveness and Revenge in the Workplace. Journal of Management, 25(5), 607-631.

Brett, J. M. (2000). Culture and negotiation. International Journal of Psychology, 35(2), 97-104. doi: $10.1080 / 002075900399385$

Brooks, J. H., \& Reddon, J. R. (2003). The Two Dimensional Nature of Remorse. Journal of Offender Rehabilitation, 38(2), 1-15. doi:10.1300/J076v38n02_01

Cohen, D., \& Nisbett, R. E. (1994). Self-protection and the culture of honor: Explaining southern violence. Personality and Social Psychology Bulletin, 20(5), 551-567. doi:10.1177/0146167294205012 
Cohen, D., \& Nisbett, R. E. (1997). Field experiments examining the culture of honor: The role of institutions in perpetuating norms about violence. Personality and Social Psychology Bulletin, 23(11), 1188-1199. doi:10.1177/01461672972311006

Cohen, D., Nisbett, R. E., Bowdle, B. F., \& Schwarz, N. (1996). Insult, aggression, and the southern culture of honor: An 'experimental ethnography'. Journal of Personality and Social Psychology, 70(5), 945-960. doi:10.1037/0022-3514.70.5.945

Cohen, D., Vandello, J., Puente, S., \& Rantilla, A. (1999). 'When you call me that, smile!' How norms for politeness, interaction styles, and aggression work together in Southern culture. Social Psychology Quarterly, 62(3), 257-275. doi:10.2307/2695863

Cross, S. E., Uskul, A. K., Gerçek-Swing, B., Alözkan, C., \& Ataca, B. (2013). Confrontation versus withdrawal: Cultural differences in responses to threats to honor. Group Processes \& Intergroup Relations, 16(3), 345-362. doi:10.1177/1368430212461962

Cross, S. E., Uskul, A. K., Gerçek-Swing, B., Sunbay, Z., Alözkan, C., Günsoy, C., . . . Karakitapoğlu-Aygün, Z. (2014). Cultural Prototypes and Dimensions of Honor. Personality and Social Psychology Bulletin, 40(2), 232-249. doi: $10.1177 / 0146167213510323$

De Dreu, C. K. W., \& Weingart, L. R. (2003). Task versus relationship conflict, team performance, and team member satisfaction: A meta-analysis. Journal of Applied Psychology, 88(4), 741-749. doi:10.1037/0021-9010.88.4.741

De Wit, F. R. C., Greer, L. L., \& Jehn, K. A. (2012). The paradox of intragroup conflict: A metaanalysis. Journal of Applied Psychology, 97(2), 360-390. doi:10.1037/a0024844 
[First Authors Last Name] Page 38

Dijke, M. v., \& Cremer, D. D. (2011). When social accounts promote acceptance of unfair ultimatum offers: The role of the victim's stress responses to uncertainty and power position. Journal of Economic Psychology, 32(3), 468-479.

doi:10.1016/j.joep.2011.03.014

Eurostat. (2016). Asylum Statistics. Retrieved from http://ec.europa.eu/eurostat/statisticsexplained/index.php/Asylum_statistics

Fehr, R., \& Gelfand, M. J. (2010). When apologies work: How matching apology components to victims' self-construals facilitates forgiveness. Organizational Behavior and Human Decision Processes, 113(1), 37-50. doi:10.1016/j.obhdp.2010.04.002

Fehr, R., Gelfand, M. J., \& Nag, M. (2010). The road to forgiveness: A meta-analytic synthesis of its situational and dispositional correlates. Psychological Bulletin, 136(5), 894-914. doi: $10.1037 / \mathrm{a} 0019993$

Gelfand, M. J., Severance, L., Lee, T., Bruss, C. B., Lun, J., Abdel-Latif, A.-H., . . Moustafa Ahmed, S. (2015). Culture and getting to yes : The linguistic signature of creative agreements in the United States and Egypt. Journal of Organizational Behavior, 36(7), 967-989. doi:10.1002/job.2026

Gilmore, D. D. (Ed.) (1987). Honor and Shame and the Unity of the Mediterranean.

Washington, DC: American Anthropological Association.

Goffman, E. (1971). Relations in public. New York: Harper Colophon Books.

Gold, G. J., \& Weiner, B. (2000). Remorse, Confession, Group Identity, and Expectancies About Repeating a Transgression. Basic and Applied Social Psychology, 22(4), 291-300. doi:10.1207/S15324834BASP2204_3 
[First Authors Last Name] Page 39

Gries, P. H., \& Peng, K. (2002). Culture Clash? Apologies East and West. Journal of Contemporary China, 11(30), 173-178. doi:10.1080/106705601200912000

Guan, X., Park, H. S., \& Lee, H. E. (2009). Cross-cultural differences in apology. International Journal of Intercultural Relations, 33(1), 32-45. doi:10.1016/j.ijintrel.2008.10.001

Guerra, V. M., Giner-Sorolla, R., \& Vasiljevic, M. (2013). The importance of honor concerns across eight countries. Group Processes \& Intergroup Relations. doi:10.1177/1368430212463451

Han, B., \& Cai, D. A. (2010). Face goals in apology: A cross-cultural comparison of Chinese and U.S. Americans. Journal of Asian Pacific Communication, 20(1), 101-123. doi:10.1075/japc.20.1.06han

Holt, J. L., \& DeVore, C. J. (2005). Culture, gender, organizational role, and styles of conflict resolution: A meta-analysis. International Journal of Intercultural Relations, 29(2), $165-$ 196. doi:10.1016/j.ijintrel.2005.06.002

Hui, C. H., Lau, F. L. Y., Tsang, K. L. C., \& Pak, S. T. (2011). The Impact of Post-Apology Behavioral Consistency on Victim's Forgiveness Intention: A Study of Trust Violation Among Coworkers. Journal of Applied Social Psychology, 41(5), 1214-1236. doi: $10.1111 /$ j.1559-1816.2011.00754.X

IJzerman, H., Van Dijk, W. W., \& Galluci, M. (2007). A bumpy train ride: A field experiment on insult, honor, and emotional reactions. Emotion, 7(4), 869-875. doi:10.1037/15283542.7.4.869 
[First Authors Last Name] Page 40

Jehn, K. A., Northcraft, G. B., \& Neale, M. A. (1999). Why Differences Make a Difference: A Field Study of Diversity, Conflict and Performance in Workgroups. Administrative Science Quarterly, 44(4), 741-763. doi:10.2307/2667054

Joshi, A., \& Roh, H. (2009). The Role Of Context In Work Team Diversity Research: A MetaAnalytic Review. Academy of Management Journal, 52(3), 599-627.

doi:10.5465/AMJ.2009.41331491

Kim, Y.-H., Cohen, D., \& Au, W.-T. (2010). The jury and abjury of my peers: The self in face and dignity cultures. Journal of Personality and Social Psychology, 98(6), 904-916. doi:10.1037/a0017936

Kirchhoff, J., \& Čehajić-Clancy, S. (2014). Intergroup apologies: Does it matter what they say? Experimental analyses. Peace and Conflict: Journal of Peace Psychology, 20(4), 430-

451. doi:10.1037/pac0000064

Lazare, A. (2004). On Apology. New York - NY: Oxford University Press.

Leary, M. R., Tambor, E. S., Terdal, S. K., \& Downs, D. L. (1995). Self-esteem as an interpersonal monitor: The sociometer hypothesis. Journal of Personality and Social Psychology, 68(3), 518-530. doi:10.1037/0022-3514.68.3.518

Leung, A. K. Y., \& Cohen, D. (2011). Within- and between-culture variation: Individual differences and the cultural logics of honor, face, and dignity cultures. Journal of Personality and Social Psychology, 100(3), 507-526. doi:10.1037/a0022151

Lewicki, R. J., Polin, B., \& Lount, R. B. (2016). An Exploration of the Structure of Effective Apologies. Negotiation and Conflict Management Research, 9(2), 177-196. doi:10.1111/ncmr.12073 
Maddux, W. W., Kim, P. H., Okumura, T., \& Brett, J. M. (2011). Cultural Differences in the Function and Meaning of Apologies. International Negotiation, 16(3), 405-425. doi: $10.1163 / 157180611 \times 592932$

May, F., Monga, A. B., \& Kalaignanam, K. (2015). Consumer Responses to Brand Failures: The Neglected Role of Honor Values Brand Meaning Management (pp. 257-291): Emerald Group Publishing Limited.

Merolla, A. J., Zhang, S., \& Sun, S. (2013). Forgiveness in the United States and China: Antecedents, Consequences, and Communication Style Comparisons. Communication Research, 40(5), 595-622. doi:10.1177/0093650212446960

Miller, W. I. (1993). Humiliation and Other Essays on Honor, Social Discomfort, and Violence. Ithaca, NY: Cornell University Press.

Neale, M. A., Northcraft, G. B., \& Jehn, K. A. (1999). Exploring Pandora's Box; The Impact of Diversity and Conflict on Work Group Performance. Performance Improvement Quarterly, 12(1), 113-126. doi:10.1111/j.1937-8327.1999.tb00118.x

Oetzel, J. G., \& Ting-Toomey, S. (2003). Face Concerns in Interpersonal Conflict: A CrossCultural Empirical Test of the Face Negotiation Theory. Communication Research, 30(6), 599-624. doi:10.1177/0093650203257841

Ohbuchi, K.-i., Kameda, M., \& Agarie, N. (1989). Apology as aggression control: Its role in mediating appraisal of and response to harm. Journal of Personality and Social Psychology, 56(2), 219-227. doi:10.1037/0022-3514.56.2.219

Peristiany, J. (Ed.) (1965). Honor and Shame: The Values of Mediterranean Society. London: Weidenfeld \& Nicholson. 
[First Authors Last Name] Page 42

Pitt-Rivers, J. (1965). Honour and social status. In J. Peristiany (Ed.), Honour and Shame: The Values of Meditteranean Society (pp. 19-77). London: Weidenfeld \& Nicolson.

Pitts, D. (2009). Diversity Management, Job Satisfaction, and Performance: Evidence from U.S. Federal Agencies. Public Administration Review, 69(2), 328-338. doi:10.1111/j.1540$6210.2008 .01977 . x$

Rodriguez Mosquera, P., Fischer, A. H., Manstead, A. S. R., \& Zaalberg, R. (2008). Attack, disapproval, or withdrawal? The role of honour in anger and shame responses to being insulted. Cognition and Emotion, 22(8), 1471-1498. doi:10.1080/02699930701822272

Rodriguez Mosquera, P., Manstead, A. S. R., \& Fischer, A. H. (2000). The role of honor-related values in the elicitation, experience, and communication of pride, shame, and anger:

Spain and the Netherlands compared. Personality and Social Psychology Bulletin, 26(7), 833-844. doi:10.1177/0146167200269008

Rodriguez Mosquera, P., Manstead, A. S. R., \& Fischer, A. H. (2002a). Honor in the Mediterranean and Northern Europe. Journal of Cross-Cultural Psychology, 33(1), 1636. doi:10.1177/0022022102033001002

Rodriguez Mosquera, P., Manstead, A. S. R., \& Fischer, A. H. (2002b). The role of honour concerns in emotional reactions to offences. Cognition and Emotion, 16(1), 143-163. doi:10.1080/02699930143000167

Schneider, P. (1969). Honor and Conflict in a Sicilian Town. Anthropological Quarterly, 42(3), 130-154. 
Schweitzer, M. E., Hershey, J. C., \& Bradlow, E. T. (2006). Promises and lies: Restoring violated trust. Organizational Behavior and Human Decision Processes, 101(1), 1-19. doi: 10.1016/j.obhdp.2006.05.005

Shafa, S., Harinck, F., Ellemers, N., \& Beersma, B. (2014). Who Are You Calling Rude? HonorRelated Differences in Morality and Competence Evaluations After an Insult. Negotiation and Conflict Management Research, 7(1), 38-56. doi:10.1111/ncmr.12024

Shafa, S., Harinck, F., Ellemers, N., \& Beersma, B. (2015). Regulating honor in the face of insults. International Journal of Intercultural Relations, 47(0), 158-174. doi:10.1016/j.ijintrel.2015.04.004

Shnabel, N., \& Nadler, A. (2008). A needs-based model of reconciliation: Satisfying the differential emotional needs of victim and perpetrator as a key to promoting reconciliation. Journal of Personality and Social Psychology, 94(1), 116-132. doi:10.1037/0022-3514.94.1.116

Struthers, C. W., Eaton, J., Mendoza, R., Santelli, A. G., \& Shirvani, N. (2010). Interrelationship Among Injured Parties' Attributions of Responsibility, Appraisal of Appropriateness to Forgive the Transgressor, Forgiveness, and Repentance. Journal of Applied Social Psychology, 40(4), 970-1002. doi:10.1111/j.1559-1816.2010.00607.x

Struthers, C. W., Eaton, J., Santelli, A. G., Uchiyama, M., \& Shirvani, N. (2008). The effects of attributions of intent and apology on forgiveness: When saying sorry may not help the story. Journal of Experimental Social Psychology, 44(4), 983-992.

doi:10.1016/j.jesp.2008.02.006 
[First Authors Last Name] Page 44

Sugimoto, N. (1997). A Japan-U.S. Comparison of Apology Styles. Communication Research, 24(4), 349-369. doi:10.1177/009365097024004002

The Guardian. (2016). Volkswagen boss apologises to America for cheating diesel emissions tests. Retrieved from https://www.theguardian.com/business/2016/jan/11/volkswagenboss-apologises-to-america-for-cheating-diesel-emissions-tests

Tomlinson, E. C., Dineen, B. R., \& Lewicki, R. J. (2004). The Road to Reconciliation: Antecedents of Victim Willingness to Reconcile Following a Broken Promise. Journal of Management, 30(2), 165-187. doi:10.1016/j.jm.2003.01.003

Triandis, H. C. (2000). Culture and conflict. International Journal of Psychology, 35(2), $145-$ 152. doi:10.1080/002075900399448

Uskul, A. K., Cross, S. E., Sunbay, Z., Gercek-Swing, B., \& Ataca, B. (2012). Honor Bound: The Cultural Construction of Honor in Turkey and the Northern United States. Journal of Cross-Cultural Psychology, 43(7), 1131-1151. doi:10.1177/0022022111422258

Van Osch, Y., Breugelmans, S. M., Zeelenberg, M., \& Bölük, P. (2013). A different kind of honor culture: Family honor and aggression in Turks. Group Processes \& Intergroup Relations, 16(3), 334-344. doi:10.1177/1368430212467475

Walfisch, T., Van Dijk, D., \& Kark, R. (2013). Do you really expect me to apologize? The impact of status and gender on the effectiveness of an apology in the workplace. Journal of Applied Social Psychology, 43(7), 1446-1458. doi:10.1111/jasp.12101

Washington Post. (2016). Turkish president apologizes for downing of Russian warplane last year. Retrieved from https://www.washingtonpost.com/world/turkey-apologizes-for- 
shooting-down-russian-warplane-last-year/2016/06/27/d969e0ea-3c6d-11e6-9e164cf01a41decb_story.html

Zechmeister, J. S., Garcia, S., Romero, C., \& Vas, S. N. (2004). Don't apologize unless you Z meàn it: A laboratory investigation of forgiveness and retaliation. Journal of Social \& Clinical Psychology, 23(4), 532-564.
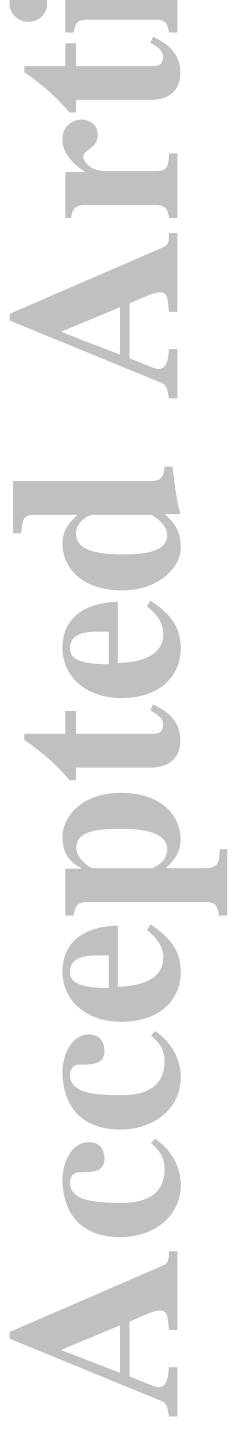
Table 1. Statistics for ANOVAs on perceived responsibility and remorse with culture, blame factor and remorse factor as independent variables

\begin{tabular}{|c|c|c|c|c|c|c|c|c|}
\hline & \multicolumn{4}{|c|}{ Responsibility } & \multicolumn{4}{|c|}{ Remorse } \\
\hline & $\boldsymbol{F}$ & $\eta_{p}^{2}$ & NL & TR & $\boldsymbol{F}$ & $\eta_{p}^{2}$ & $\mathbf{N L}$ & TR \\
\hline Culture & .68 & & & & $12.41 * *$ & .04 & & \\
\hline Blame factor & $56.67 * *$ & .15 & & & $20.30 * *$ & .06 & & \\
\hline Remorse factor & $60.67 * *$ & .16 & & & $35.26^{* *}$ & .10 & & \\
\hline Blame * Remorse & $37.56^{* *}$ & .10 & & & $22.58 * *$ & .06 & & \\
\hline Culture * Blame & $7.77 *$ & .04 & $50.36^{* *}$ & $11.91^{* *}$ & $19.05^{* *}$ & .08 & $59.67 * *$ & $10.03 * *$ \\
\hline Culture * Remorse & $11.82 * *$ & .035 & $46.87 * *$ & .47 & $19.05^{* *}$ & .06 & $50.24 * *$ & 1.31 \\
\hline Three-way interaction & $3.81^{\wedge}$ & .01 & & & $8.05 *$ & .02 & & \\
\hline
\end{tabular}

Note: $* * p>.001 ; * p>.05 ; \wedge p=.052$ 


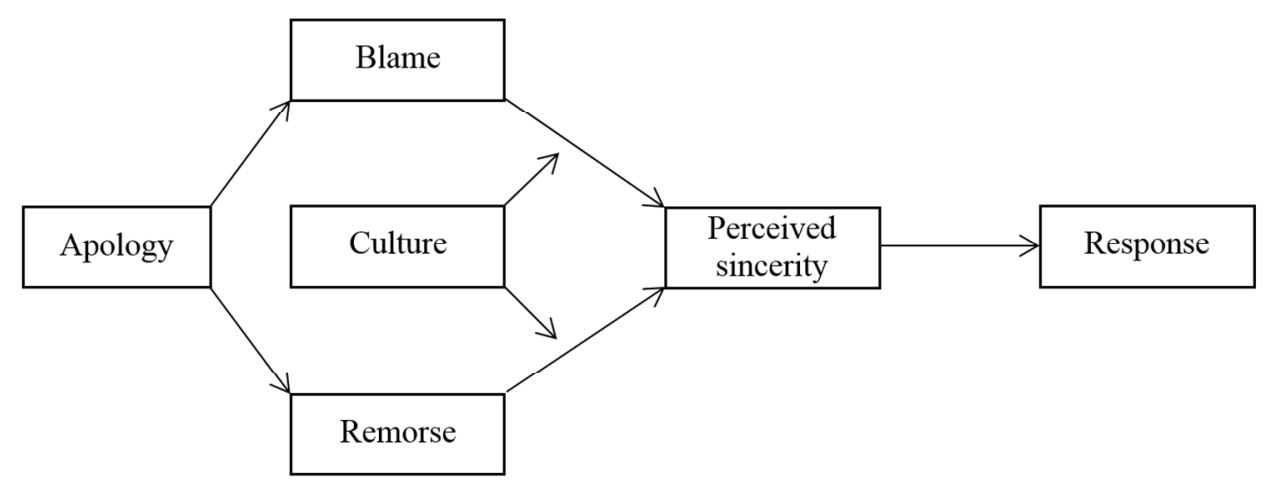

Figure 1. Conceptual model.

$123 \times 49 \mathrm{~mm}(300 \times 300 \mathrm{DPI})$



Journal of Applied Social Psychology

This article is protected by copyright. All rights reserved. 


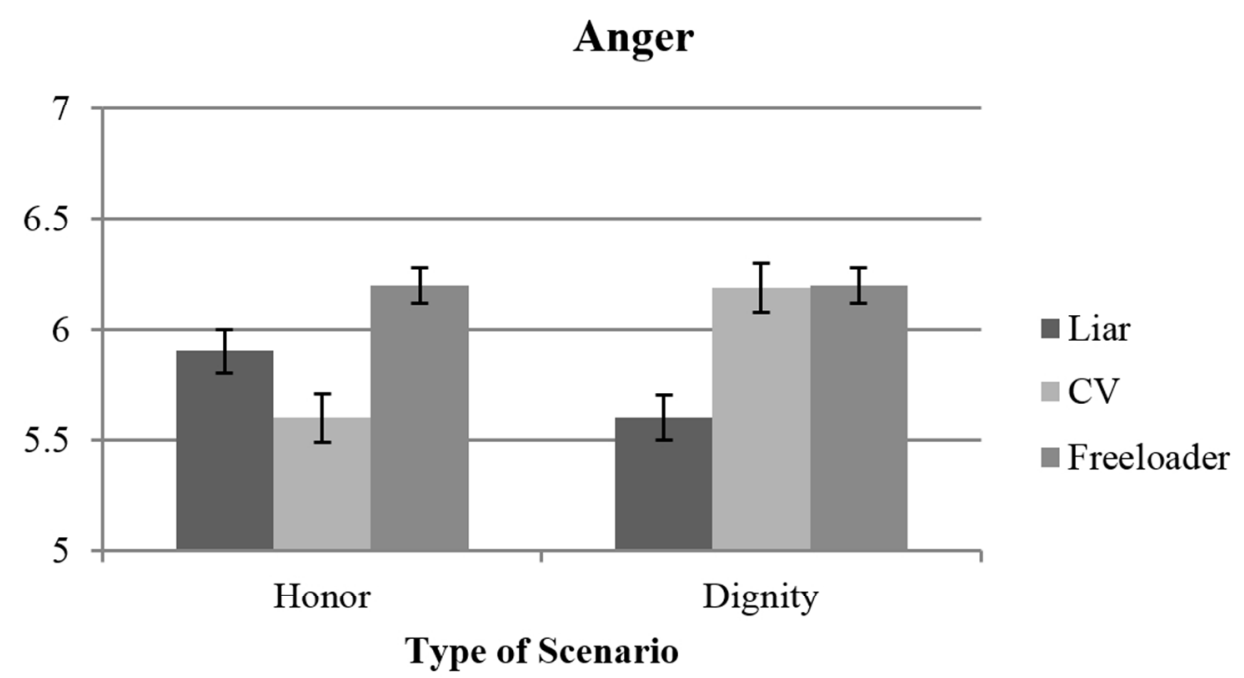

Figure 2. Anger levels in response to different scenarios.

$96 \times 54 \mathrm{~mm}(300 \times 300$ DPI $)$

Journal of Applied Social Psychology

This article is protected by copyright. All rights reserved. 


\section{Responsibility taken}

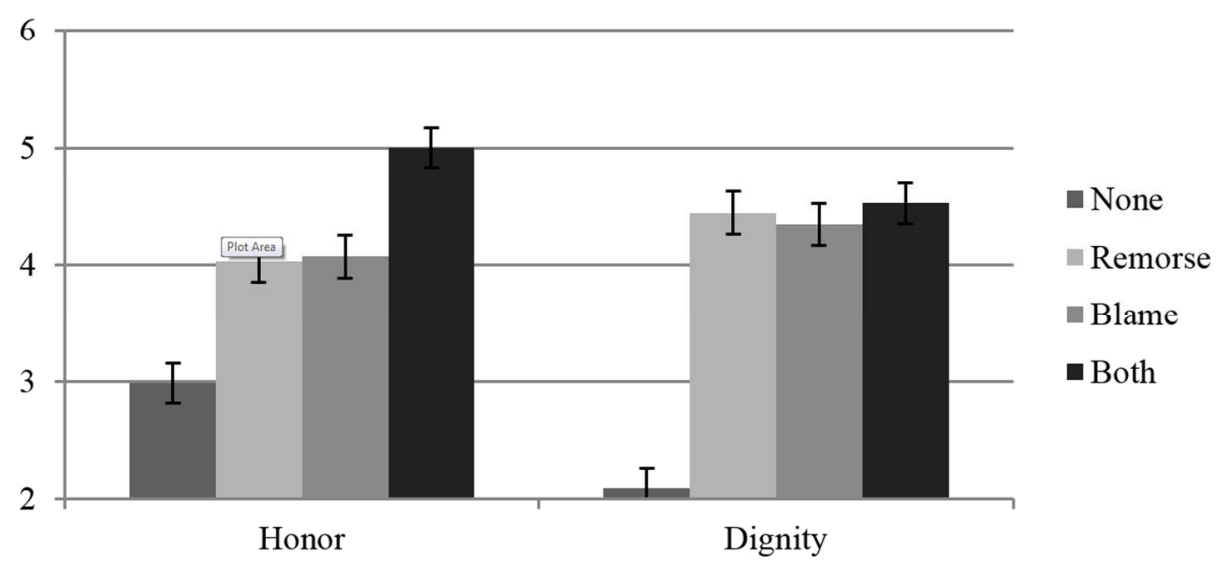

Figure 3. Perceived responsibility taken for the offense per condition and cultural group.

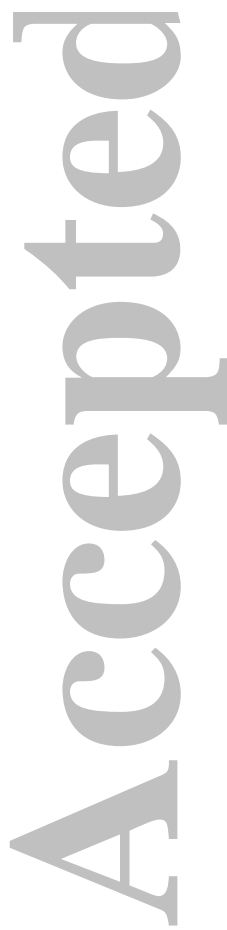
$108 \times 57 \mathrm{~mm}(300 \times 300 \mathrm{DPI})$ 


\section{Expressed remorse}



Figure 4. Perceived expression of remorse for the offense per condition and cultural group. $108 \times 54 \mathrm{~mm}(300 \times 300 \mathrm{DPI})$






\section{Inclination to forgive/retaliate}



Figure 5. Inclinations to forgive (and retaliate less) per condition and cultural group.

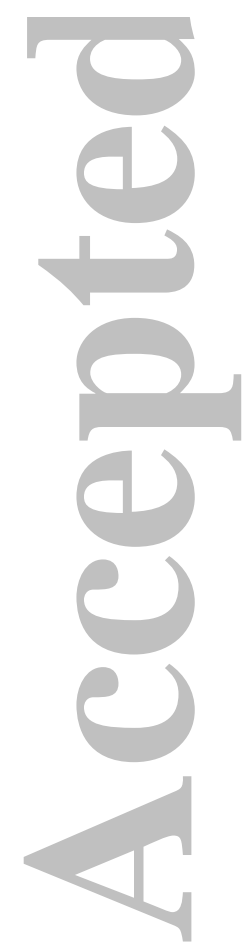

$$
108 \times 56 \mathrm{~mm}(300 \times 300 \text { DPI) }
$$




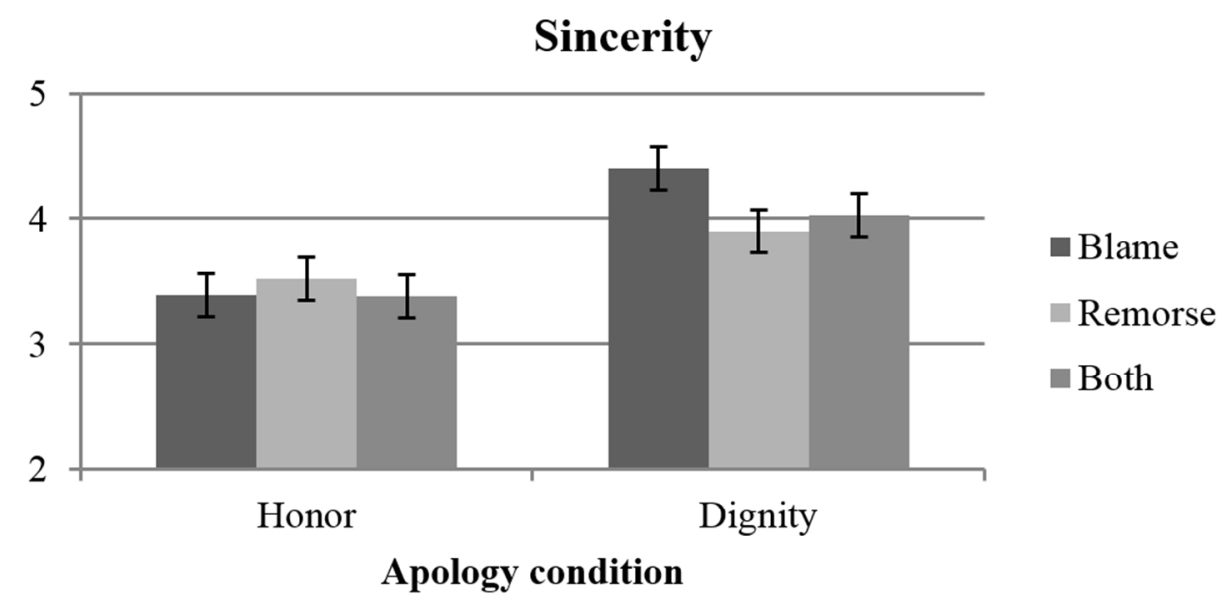

Figure 6. Perceived sincerity of the apology per condition and cultural group. $94 \times 48 \mathrm{~mm}(300 \times 300 \mathrm{DPI})$ 


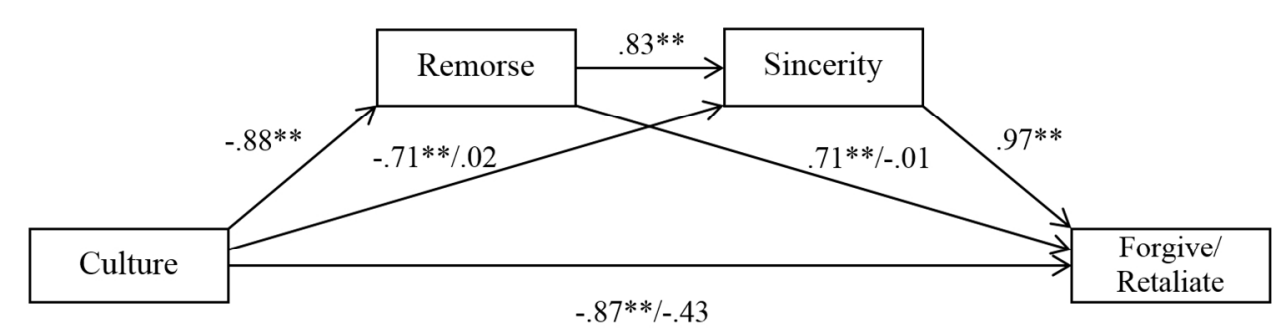

Figure 7. Mediation analysis for the indirect effect of culture on behavioral inclinations via perceived remorse and sincerity. NB. For culture, $1=$ Dignity, 2 = Honor.

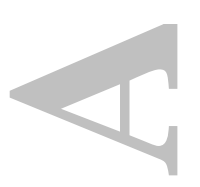

$133 \times 40 \mathrm{~mm}(300 \times 300$ DPI)

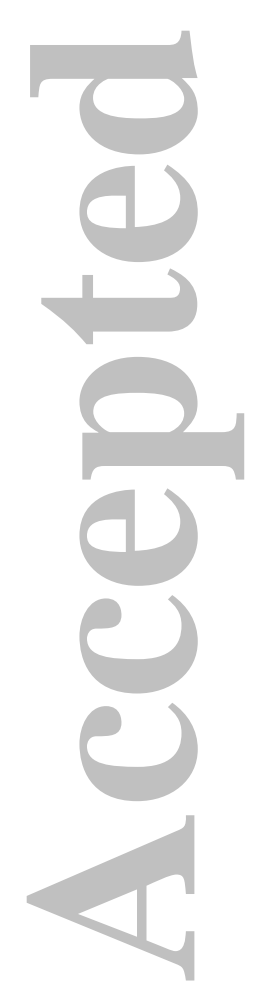




\section{Appendix A. Scenarios}

\section{Scenario 1: Liar}

Imagine you work at a consultancy company. In a few days you and your colleagues will have a meeting with the board members of one the most important clients. During this meeting, your team will present the outcome of a thorough investigation of your client's assets and ways to improve their finical position. As you and your team are preparing for this meeting, you notice that important documents, containing the most recent figures on turnover and costs are missing. These documents are essential for making a correct analysis and acquiring new copies will take a few days at least, setting your progress back considerably. While the entire team is busy looking for the documents, one of your team members says that you are the last person who had them and that you are responsible for the loss and consequent delay. You tell your team member you had nothing to do with the documents. The two of you get into an argument in front of the entire team, and your colleague says: "You are a dirty liar!"

The documents are still missing but your colleague has calmed down after a while. When you continue the meeting, he says:

- I am sorry that I called you a liar (expression of blame).

- I am sorry, you didn’t deserve being called a liar (expression of remorse).

\section{Scenario 2: CV}

Imagine that in your company a senior positon has become available. This managerial position is one pay grade above your current position and offers more flexibility in working hours as well as better carrier perspectives. You are very excited about this position and expect 
that it is feasible that you qualify for the job. You decide to apply for it. To do so, you contact your company's HR officer and ask him/her to forward your application and resume to the head of the department. Two weeks later, you receive the company newsletter saying that the deadline for the application has passed and that all applicants have been invited for the selection procedure. You are very surprised, because you have not received such an invitation and were not even contacted about the application. When you inform about this, the HR officer tells you that s/he never submitted your resume to the head of department. As a result, you are now unable to contend for the position. S/he says: "Your resume was rather weak so you wouldn't have qualified anyway."

A little while later, the HR officer comes by your office and apologizes by saying:

- I am sorry that I held back your résumé (expression of blame).

- I am sorry, you deserved a chance (expression of remorse).

\section{Scenario 3: Freeloader}

Imagine working at a marketing company. Together with a colleague, you have worked hard on landing a new contract. This new contract is with a very important client and if you build the relationship well, this contact has the potential to generate high revenues for the company in the next few years. After closing the contract, you decide to take a few days off to get some rest. After a while, when your performance review is due, you expect a very positive revaluation and maybe even a small bonus as a reward for your accomplishment. However, your manager sees things differently as he is under the impression that although you were part of the team, it was your colleague that did most of the work. When you discuss this with other colleagues, they do 
not seem very surprised. It appears that during your absence, your team mate has not only taken all the credit for closing the new contract, but has even spread rumors around the office that you hardly contributed to the process and were only hitching a ride on someone else's wagon. During a meeting, s/he calls you a freeloader.

Your colleague approaches you after a short while and says:

- I am sorry that I spread those rumors around (expression of blame).

- I am sorry, you deserved the credit (expression of remorse).
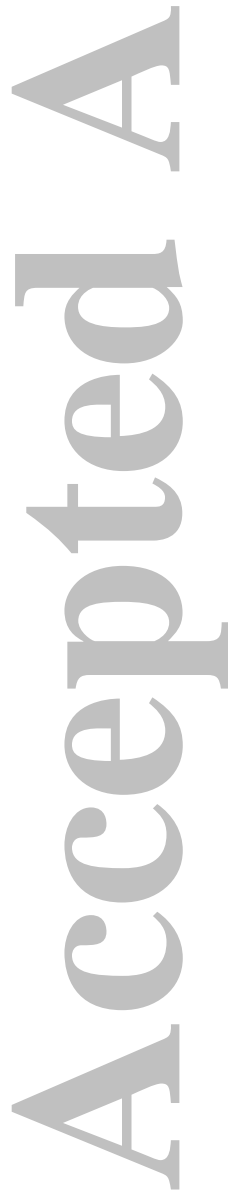


\section{University Library}

\section{- M M N E R VA A gateway to Melbourne's research publications}

Minerva Access is the Institutional Repository of The University of Melbourne

Author/s:

Shafa, S;Harinck, F;Ellemers, N

Title:

Sorry seems to be the hardest word: Cultural differences in apologizing effectively

Date:

2017-10-01

Citation:

Shafa, S., Harinck, F. \& Ellemers, N. (2017). Sorry seems to be the hardest word: Cultural differences in apologizing effectively. Journal of Applied Social Psychology, 47 (10), pp.553-567. https://doi.org/10.1111/jasp. 12460.

Persistent Link:

http://hdl.handle.net/11343/293202 